\title{
The methodology of increasing the functional safety of aviation enterprises
}

\author{
Temnikov Volodymyr \\ Institute of Information and \\ Diagnostic Systems \\ National Aviation University \\ Kyiv, Ukraine \\ temnikov_v@ukr.net
}

\author{
Pavlenko Petro \\ Institute of Information and \\ Diagnostic Systems \\ National Aviation University \\ Kyiv, Ukraine \\ petrpav@ukr.net
}

\author{
Temnikova Olena \\ Faculty of Applied \\ Mathematics \\ Igor Sikorsky KPI \\ Kyiv, Ukraine \\ temnikova_elena@ukr.net
}

\author{
Temnikov Andrii \\ Institute of Information and \\ Diagnostic Systems \\ National Aviation University \\ Kyiv, Ukraine \\ temnikoff@ukr.net
}

\begin{abstract}
Functional safety of aviation enterprises (control towers and airports) depends significantly on the state of the system "Aviation Security Service - entities that commit acts of unlawful interference in the operation of airports" and the functional condition of the Aviation Security Service staff and air traffic controllers. Therefore, its increase can be achieved only with the systematic application of organizational measures and measures aimed at reducing the human factor's impact on the effectiveness of the Aviation Security Service staff and air traffic controllers. The article describes the methodology for improving the operational safety of the aviation enterprise, based on the developed models and the methods for managing the levels of the state of the system, employees of the Aviation Security Service and air traffic controllers.
\end{abstract}

Keywords - aviation safety, aviation enterprise, Aviation Security Service, air traffic controller, functional state, psychophysiological resource

\section{INTRODUCTION}

Analytic analysis shows that the flight safety and aviation security in many countries, including Ukraine, are at an unsatisfactory level [1], which is manifested, in particular, in the inability to prevent terrorist acts.

Air traffic controllers (from the correctness and literacy of their actions to a large extent, the flight safety) and Aviation Security Service personnel play an important role in ensuring aviation safety (the correctness and literacy of their actions determine the effectiveness of protection of aviation enterprises from acts of illegal interventions (AII) in their activities). This determines the urgency of solving the problem of increasing the level of functional safety of aviation enterprises.

The main causes of accidents caused by the actions of employees of aviation enterprises are [2-4] inadequate actions of Aviation Security Service employees caused by insufficiently competent organization of these services and unintentional mistakes of air traffic controllers and Aviation Security Service employees caused by their being in an inadequate physical, physiological or mental state (human factor).
As it is noted in [2], in order to effectively counter the security threats, a set of measures (technical measures) aimed at reducing the human factors influence on security should be applied. Therefore, the authors focus on the direction of systemic application of organizational measures and measures aimed at reducing the human factor impact on the functional safety of aviation enterprises (control towers and airports).

Based on the foregoing, as the main areas for improving the safety of aviation enterprises, we define the following:

1. Improving the effectiveness (quality of organization) of the Aviation Security Service work to counteract the subjects (malefactors) committing AII to the activities of aviation enterprises (SAII).

2. Improving the effectiveness of countering threats caused by human factors, in the first place - improving the efficiency of airport employees, on whose actions security depends, and air traffic controllers.

To implement these directions, the following the methods were developed:

- the method of increasing the effectiveness (quality) of the Aviation Security Service;

- the method to improve the efficiency of monitoring the functional conditions of air traffic controllers and Aviation Security Service employees;

- the method of adaptive management of psychophysiological resources of employees of the aviation enterprise;

- the way to improve the information security of decision-makers.

\section{THE METHOD OF INCREASING THE EFFICIENCY (QUALITY) OF THE ACTIVITIES OF AVIATION SECURITY SERVICES}

The method is based on the calculation of the probabilities of the transition of a complex Aviation Security Service-SAII system from the state of the aviation enterprise's security to other states in which the system may prove to be due to the commission of acts of unlawful interference in the activities of the airport by intruders. The number of states of the Aviation 
Security Service-SAII system is determined by the structure of the Aviation Security Service. For assessing the effectiveness of the various Aviation Security Service units, for example, the following conditions can be selected: the status of the violation of the access mode (with unauthorized intervention of the attacker into the controlled area), the state of violation of the intra-object mode (when an intruder performs unauthorized actions in the controlled zone), the state of seizure of the airport or air ship.

Increasing the effectiveness of the Aviation Security Service can be achieved by modeling the complex system "Aviation Security Service-SAII".

To build the model of the "Aviation Security ServiceSAII" system, the processes in each of its subsystems were analyzed and a scheme for coupling the subsystems was developed, proceeding from the way they interacted in solving the problems facing the Aviation Security Service.

Initial assumptions characterizing the interaction of the elements of the "Aviation Security Service-SAII" system:

1. The initiator of the interaction between Aviation Security Service and SAII are intruders - they are threatened by security. The aggregate of SAII is viewed as a multielement system, united by the unity of purpose - the successful completion of an act of unlawful interference in the activities of the airport.

2. Subsystems Aviation Security Service, interacting with malefactors, operate autonomously, while the result of interaction of one subsystem does not always have to be positive, while the single negative result of interaction between Aviation Security Service and intruders is not its final act.

3. Transitions of the system from one state to another are caused by the manifestation of a number of factors (a set of threats), which are regarded as a flow of events occurring at random instants of time. Since the probability of simultaneous occurrence of two or more events is much less than one, then the event flow will be considered ordinary. The flow of events is not avalanche-like.

When these assumptions are accepted, the probability of occurrence of an event in a certain time interval can be considered independent of the number of events at other time intervals, i.e. the flow of events can be regarded as a Poisson flow without aftereffect and described by the Poisson distribution known in probability theory.

We will assume that all probability characteristics of events for any moment of time is determined only by this moment of time and do not depend on the background. This property, together with the finiteness of the number of states of the system, makes it possible to assert that the process under investigation is a Markov random process.

The problem is to determine the probabilities $\mathrm{P}_{0}(\mathrm{t}), \mathrm{P}_{\mathrm{i}}(\mathrm{t}), \ldots, \mathrm{P}_{\mathrm{n}}(\mathrm{t})$ of finding the system (or its subsystem) in a particular state as a function of time.

As a model of the "Aviation Security Service-SAII" system, a graph model describing the system through its possible states and transitions from one state to another is proposed. The mathematical formalization of the model is the Kolmogorov differential equations system with respect to the probabilities $\mathrm{P}_{0}(\mathrm{t}), \mathrm{P}_{\mathrm{i}}(\mathrm{t}), \ldots, \mathrm{P}_{\mathrm{n}}(\mathrm{t})$. Solve this system by moving to the Cauchy problem and applying Laplace transforms or numerical the methods.

A quantitative solution of Kolmogorov's system of differential equations is possible under the condition of a sufficient number of statistical data on the probability of a system transition from one state to another. However, at the present time such information is not available, which makes the solution of the problem impossible using direct statistical the methods.

To obtain the statistical data necessary to solve the Kolomogorov equations (determining the probabilities of transitions of the Aviation Security Service-SAII system from one state to another), a the method based on the qualimetric models of operational procedures performed by the Aviation Security Service staff was developed. The application of the developed models and the method makes it possible to calculate the probabilities needed to solve the Kolmogorov equations on the basis of expert estimates [5].

\section{THE METHOD FOR IMPROVING THE EFFICIENCY OF MONITORING THE FUNCTIONAL CONDITIONS OF AIR TRAFFIC CONTROLLERS AND AVIATION SECURITY SERVICES}

One of the main reasons for the influence of the human factor on the functional safety of the aviation enterprise is the finding of a person in an inadequate psychophysiological state [6]. Therefore, it is possible to significantly improve the effectiveness of countering threats caused by the human factor by improving the control of the functional condition of air traffic controllers and Aviation Security Service employees at various stages of their professional activity: determining the ability of a person to perform the duties of an air traffic controller or a Aviation Security Service employee when hiring and passing periodic control, readiness of air traffic controllers and Aviation Security Service staff to perform professional (official) duties during pre-shift control, and improve the efficiency of services, evaluating the ability and willingness of the staff to carry out professional airports (official) duties.

To assess the ability and readiness of a person to perform professional (official) duties, it is proposed to introduce a new indicator - a psychophysiological resource (PPR), determined on the basis of assessing the state of the cardiovascular system of a person. This approach is due to the fact that the state of the cardiovascular system is an integral characteristic that allows to assess the state of the regulatory systems of the human body and its adaptive capabilities.

At present, the most informative noninvasive the method of quantitative assessment of the functional state of the human body is the recognition of heart rate variability - the variability of the duration of intervals of consecutive heartbeat cycles for certain time intervals $[7,8]$.

When recruiting and passing periodic monitoring, the state of the cardiovascular system can be assessed using the activity 
index of regulatory systems (RSAI), which allows differentiating different degrees of stress in the human body's regulatory systems and assessing the adaptive capabilities of the body. RSAI is calculated in points according to a special algorithm that takes into account the statistical indices, the histogram of the distribution of cardiointerval durations, and the spectral analysis of the cardiointervals.

The functional state of the examined person according to the results of the RSAI calculation can be assigned to one of the classes [8]: the state of the norm (state of satisfactory adaptation), the state of the functional stress, the state of overstress (state of unsatisfactory adaptation), etc. Taking into account the value of RSAI, perform official duties.

The basis for admission or non-admission of air traffic controllers and Aviation Security Service employees to professional activities for health reasons are the results of premedical medical examination (one of the purposes of which is the timely identification and removal from work of persons with initial forms of the disease and reduced performance due to fatigue associated with insufficient sleep, excessive physical exertion, violation of the rest regime or other reasons.

The scope of the currently conducted pre-medical medical control is clearly not enough to make an informed decision on admission or non-admission to work. Objective results of medical pre-control monitoring can be obtained only on the basis of its improvement by introducing new progressive the methods for determining the functional status of air traffic controllers and Aviation Security Service staff, identifying their symptoms of depression, fatigue, stress, and automating the processing of results and the decision-making process.

In order to improve the quality of pre-flight monitoring of the functional state of an aviation enterprise employee, it is suggested, as in the case of recruitment and periodic monitoring, to evaluate its psycho-physiological resource. The definition and analysis of the PPR will help the doctor in setting the right diagnosis of the state of health and making a more informed decision about the degree of the person's readiness to perform his professional duties.

As an indicator of the person's readiness to perform professional duties, it is suggested to use the stress index of regulatory systems (SI) proposed by prof. Bayevsky R.M. [7]. The SI is determined by an electrocardiogram by measuring the variability of the heart rate. In the norm, SI varies between 80 and 150 conventional units.

During the shift, the accidental uncontrollable impacts (stress loads, climatic and other conditions in which the airport staff work) have a negative impact on the performance of the air traffic controller and the Aviation Security Service officer. When exposed to stressful loads, this indicator for air traffic controllers and employees of Aviation Security Service people with a healthy cardiovascular system - can increase to 200-300, and the higher this index, the greater the level of stress.

Functional status indicators obtained as a result of precontrol monitoring should be entered in the database. Based on the results of pre-control monitoring, there should be weighted recommendations for maintaining the human condition at the level necessary for its production activities and evaluating the effectiveness of rehabilitation measures [9, $10]$.

\section{THE METHOD OF ADAPTIVE MANAGEMENT OF THE PSYCHOPHYSIOLOGICAL RESOURCE OF EMPLOYEES OF AN AVIATION ENTERPRISE}

Increase the functional safety of aviation enterprises by reducing the impact of human factors by authors proposed by managing the functional state of their employees, on the correctness of whose actions it depends (air traffic controllers and Aviation Security Service employees), during the working shift.

To describe the operation of the functional state management system of the aviation enterprise employees, the model presented in Fig. 1 is developed.

The main subsystems of the adaptive control model are the control object and the control system. The object of control is a person who, during the entire work shift, is exposed to regular information and physical loads (input effects X, which can be indicated by their quantitative parameters), and also to stress stresses $\mathrm{W}$ acting according to a random law. Under the influence of these effects, a person can be in one of the regulated psychophysiological conditions (PFS) (calm state, states of varying degrees of fatigue, drowsiness, anxiety, a certain emotional state) $[6,11]$.

In real conditions, a person's work during a shift is accompanied by a change in his state. This may be due to fatigue, spontaneous changes in his physical and emotional state, other reasons.

The task of the management system is to maintain the level of human capacity required for the successful performance of professional duties, that is, a functional (psychophysiological) state in order to be able to perform professional duties. In the role of the management system, the heads of command and control points of the airport and other persons making managerial decisions act.

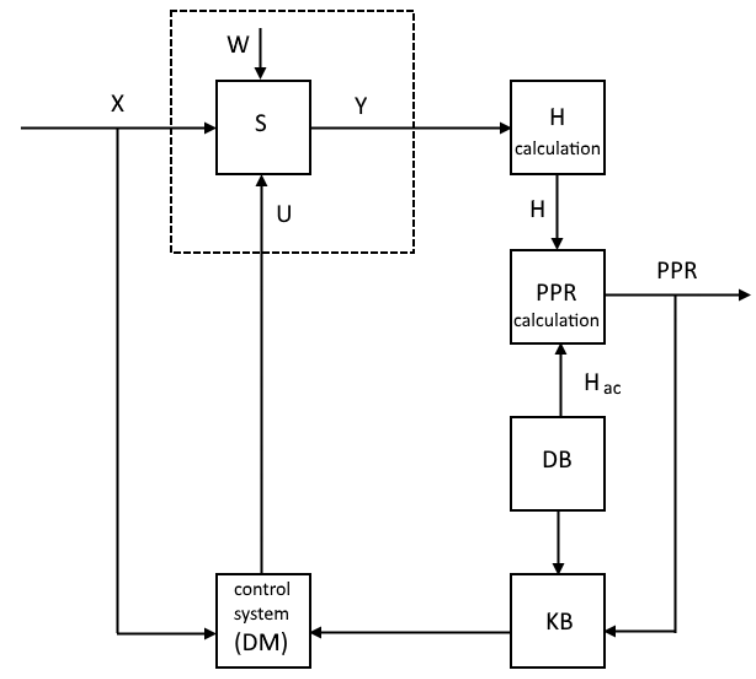

Fig.1. Model of adaptive management of the functional condition of employees of the aviation enterprise 
The solution of the problem of effective control of a person's working capacity as an object of control on the part of a control system is in the field of managing his states and consists in improving the quality of control actions U.

The output of the control object $\mathrm{Y}$ is the parameters characterizing the change in the functional state of the person during the shift.

The change in the internal state of the control object (the parameters characterizing the change in the person's PPR during the shift) determines the urgency of developing a management system model that takes into account these changes.

The developed model of the subsystem, separated in Fig. 1 by dashed lines, taking into account changes in the internal state of the person - the control object, has the form:

$$
\begin{aligned}
& Y=f(X, U, W) \\
& M=\left\{X, A_{x}, Y, B_{y}, S, T, \alpha, \beta\right\},
\end{aligned}
$$

where $\mathrm{X}$ is the set of values of the input parameters; $\mathrm{Ax}$ is the space of functions describing the input effects; Y - set of values of output parameters; By - the space of functions that describe the change in the values of output parameters in time, $\mathrm{S}$ is the set of values of the variables that characterize the functional state of a person, $\mathrm{T}$ is an ordered set of time instants, $\alpha$ is a function characterizing the dependence of the elements of a set of human states on input parameters (information and physical loads ) and the initial data obtained during the pre-medical and psychophysiological control of the Aviation Security Service staff; $\beta$ is the output function characterizing the dependence of the elements of the set $\mathrm{Y}$ on the values of the input parameters and the internal state of a person.

As with pre-term psychophysiological control, it is proposed to use the characteristics (parameters) of the state of the cardiovascular system as output parameters $y(t)$ during the shift. Based on these characteristics, the integral characteristic $\mathrm{H}$ calculated in the Baevsky stress indices is determined.

The values of $\mathrm{h}(\mathrm{t})$ are compared with the acceptable (permissible) values, which are regulated by regulatory documents for different working conditions of the aviation enterprise employees (air traffic controller and Aviation Security Service employee), calculated for each employee individually and presented in the relevant database (DB).

Deviation of the values of the parameters $h(t)$ from the acceptable values is considered as a criterion of efficiency, which allows to assess the readiness of the employee of the aviation enterprise to perform professional duties. As such a criterion, it is proposed, as well as at the two previous stages of control, to use the indicator "psychophysiological resource", determined on the basis of assessing the state of the cardiovascular system of a person. It is known that the state of the cardiovascular system is an integral characteristic that allows to assess the state of the regulatory systems of the human body and its adaptive capabilities.

The developed model is the basis for constructing a the method for improving the quality of control over the actions of
Aviation Security Service employees during the working shift from the part of the persons making managerial decisions.

The essence of adaptive management of the level of aviation security of the airport with the application of the developed model consists in simultaneous monitoring, forecasting and management of the functional state of a person.

Forecasting the change in the functional state of a Aviation Security Service employee during the shift is proposed to be carried out on the basis of modeling his functional activity in various situations on simulators. The test impacts of the Aviation Security Service employee's work on the simulators are chosen in such a way that it is possible to unequivocally determine a person's reaction (the degree of change in his functional state) in real practical situations (with real information, physical and stressful effects).

The developed model of adaptive control of the functional state of a person is the basis for managing the psychophysiological resource of Aviation Security Service employees, increasing their readiness to perform professional duties, and, consequently, the level of aviation security of the airport.

\section{INCREASING THE INFORMATION SECURITY OF DECISION- MAKERS}

One of the reasons for the accidents may be the insufficient validity (nonoptimality) of the actions of persons controlling the work of the command and control tower and airport services and taking managerial decisions to organize their activities (including the admission / non-admission of air traffic controllers and Aviation Security Service staff to the performance of professional duties). Inadequate validity of the actions of the decision-maker can be caused by a lack of information on the state of the system of counteracting the Aviation Security Service and SAII and the functional state of the employees.

In order to improve the quality of pre-control monitoring by a doctor who is a decision maker on admission / non-admission of aviation enterprise employees to work, a knowledge base has been developed in which, based on an improved the methodology for assessing a person's readiness to perform professional duties, an appropriate system of rules for the use of information contained in relevant databases. The application of this knowledge base allows the specialist (doctor) to take into account the dynamics of the change in the functional state of a person from shift to shift, the trend of changes in the PPR at the end of the shift with respect to the PPR at the beginning of the shift (based on the results of pre-shift and post-shift psychophysiological control), and other characteristics.

Persons who make decisions regarding the hiring of job seekers and who make a conclusion about the ability of the applicant to perform job duties must take into account in his work:

- parameters characterizing the human condition, determined during the tests, consisting in the impact on the applicant of the dosed information load; 
- the results of physical, physiological and mental control (medical control) conducted during periodic checks;

- the results of each pre-shift medical check of the physical, physiological and mental state carried out.

To improve the efficiency of monitoring the change in the functional state (degree of fatigue and emotional state) of air traffic controllers during the working shift, carried out by the decision-maker, the senior air traffic controller, a system of information support for making operational decisions has been developed. Its work is based on the analysis of the parameters of the speech signal generated during the audio exchange of the air traffic controller members of flight crews [12, 13].

This system is constructed using the methods of theory of pattern recognition and includes in its composition the subsystems of preliminary processing of the speech signal, its parametrization and classification.

\section{CONCLUSIONS}

1. Increase the functional safety of aviation enterprises (command and control points and airports) is proposed on the basis of:

- increasing the effectiveness (quality) of controlling the levels of ability and readiness of employees of aviation enterprises, on the correctness of whose actions their safety (air traffic controllers and Aviation Security Services) depends, to perform professional duties;

- improving the quality of control over the actions of employees of aviation enterprises during the work shift;

- raising the awareness of managers and other persons making decisions on the compliance of employees' functional status with the required (acceptable) level.

2. Reducing the impact of the human factor, which is one of the main causes of accidents, on the safety of aviation enterprises can be achieved on the basis of improving the psychophysiological control during the admission of a staff member, conducting periodic and pre-control monitoring based on the analysis of the integral indicator - the state of the cardiovascular system .

3. To assess the state of the cardiovascular system of a person in determining the ability (at employment and periodic monitoring) and readiness (during pre-control monitoring) of a person to perform professional duties is proposed on the basis of the results of the calculation of the activity index of human regulatory systems (RSAI) and the index stress (SI), based on the analysis of variability of heart rhythms.

4. As an indicator of a person's psychophysiological condition characterizing his willingness to perform professional duties, it is suggested to use the "psychophysiological resource", which means the excess of the calculated values of RSAI and SI over their acceptable levels.
5. Since the state of a person's working capacity dynamically changes in the real conditions of a working shift, it is suggested that the formation of the functional state of the employees of the aviation enterprise be carried out using the developed the method of adaptive management of a psychophysiological resource.

6. To increase the level of information security, a knowledge base has been developed (to increase the validity of decisions made by a specialist performing pre-control monitoring) and an information support system for making operational decisions (to increase the validity of decisions of senior air traffic controllers controlling the work of air traffic controllers during the shift).

\section{REFERENCES}

[1] Safety review, State Aviation Administration of Ukraine, 2016, 25 p. (in Ukrainian).

[2] Doc 9859 "Safety Management Manual," International Civil Aviation Organization, 3rd ed., 2013, 251 p.

[3] Doc 8973 “Aviation Security Manual," International Civil Aviation Organization, 9th ed., 2014, 818 p.

[4] Doc 9808 "Human factors in civil aviation security operations" // International Civil Aviation Organization, 2002, 120 p.

[5] O. Zaritskiy, P. Pavlenko, A. Tolbatov, "Data representing and processing in expert information system of professional activity analysis," Modern Problems of Radio Engineering, Telecommunications and Computer Science, Proceeding of the 13th International Conference on TCSET, 23-26 February, 2016, Lviv, Ukraine, Lviv Polytechnic national University, Lviv, 2016, pp. 718-720.

[6] V.A. Temnikov, "Principles of automatic intra-shift control of operators' access to information systems resources", Bulletin of Volodymyr Dahl East Ukrainian National University, 2012, №8(179), p.1, pp.184-190 (in Russian).

[7] R.M. Bayevsky, O.I. Kirillov, S.Z. Kletskin, Mathematical analysis of heart rate changes under stress. Moscow: Nauka, 1984, 220 p. (in Russian).

[8] R.M. Bayevsky, A.P. Berseneva, Assessment of the adaptive capabilities of the body and the risk of developing diseases. Moscow: Medicine, 1997, 265 p. (in Russian).

[9] P. Pavlenko, O. Zaritskyi, "Classification of decision making informational models as part of aircraft control system," Methods and Systems of navigaton and motion control (MSNMC) "IEEE-2016": The 4th International Conference, December 14-15, 2016, Kiev: National Aviation University, 2016, pp. 228-231.

[10] P. Pavlenko, O. Zaritskiy, V. Sudic, S. Tolbatov, A. Tolbatov, O. Viunenko, O. Tolbatova, V. Tolbatov, "Theoretical Bases, Methods and Technologies of Development of the Professional Activity Analytical Estimation Intellectual Systems," Advanced information and communication technologies - 2017 (AICT-2017): The 2nd International conference, July 4-7, 2017, Lviv, Ukraine, 2017, pp. 101104.

[11] V.A. Temnikov, A.V. Peteichuk, "The concept of the construction of an automatic system for ATC," Natural and Technical Sciences, 2015, issue 54, III (6), pp.52-54.

[12] V.A. Temnikov, "Principles of construction of decision-making systems in the process of information security management," Management, navigation and communication systems, 2017, issue 4(44), pp. 119-121 (in Ukrainian).

[13] V.M. Mihaylenko, V.A. Temnikov, A.V. Temnikov, "Principles of constructing support systems for operational decision-making in the air traffic control tower," Science and Education a New Dimension. Natural and Technical Sciences, 2017, issue 140, V(15), pp. 33-35. 